\title{
Identification and Quantification of Physicochemical Parameters Influencing Chlorophyll-a Concentrations through Combined Principal Component Analysis and Factor Analysis: A Case Study of the Yuqiao Reservoir in China
}

\author{
Ran Chen, Meiting Ju *, Chunli Chu *, Weiqiang Jing and Yuqiu Wang \\ College of Environmental Science and Engineering, Nankai University, Tianjin 300350, China; \\ chr944@163.com (R.C.); jasonjing@gatech.edu (W.J.); yqwang@nankai.edu.cn (Y.W.) \\ * Correspondence: jumeit@nankai.edu.cn (M.J.); chucl@nankai.edu.cn (C.C.); \\ Tel.:+86-138-2098-8813 (M.J.); +86-138-2138-5387 (C.C.); Fax: +86-222-350-6446 (C.C.)
}

Received: 8 March 2018; Accepted: 22 March 2018; Published: 23 March 2018

\begin{abstract}
Algal outbreaks caused by excessive nutrients in lakes result in eutrophication. Chlorophyll-a, as a primary productivity feature, is used as a representative index of algal presence in lakes. Physicochemical parameters are known to affect the type and amount of nutrients in lakes, which are related to eutrophication. In this study, factor analysis was used in conjunction with principal component analysis to reveal the relationship between chlorophyll-a and its associated parameters. The combination of these two methods helps to identify the main influencing parameters by quantifying the respective extent of parameters using FA, after which the meaning is explained by PCA. We investigate physicochemical parameters, including temperature, dissolved oxygen (DO), $\mathrm{pH}$, suspended solids, chemical oxygen demand (COD) and five-day biochemical oxygen demand, as well as nutrients, such as ammonium, nitrite, nitrate, total nitrogen, and total phosphorus (TP). Yuqiao Reservoir, an important drinking water source in northern China, has been affected by eutrophication for years. Analysis was performed using daily monitoring data of physicochemical parameters and chlorophyll-a concentrations collected from Yuqiao Reservoir between 2003 and 2014. Results show that main parameters affecting chl-a concentrations are TP, temperature, DO, COD, and nitrogen, with correlation coefficients of $0.977,1.983,1.797$, and 1.595 , respectively.
\end{abstract}

Keywords: eutrophication; Yuqiao Reservoir; principal component analysis; factor analysis; environmental management

\section{Introduction}

Eutrophication caused by algal outbreaks can lead to a series of problems, such as the degradation of water quality and massive death of organisms [1-4]. The input and accumulation of nitrogen and phosphorus has been identified as the most important sources of eutrophication [5-7]. There is a preliminary consensus that phosphorus dominates primary production in freshwater lakes, while nitrogen controls the productivity of marine systems [6,8,9].

With increasing agricultural and industrial activities, eutrophication has become one of the most serious environmental problems affecting freshwater lakes and reservoirs [10,11]. Studies performed in lakes have revealed algal outbreaks are related to many factors, including nutrient availability; physical and chemical parameters; and meteorological conditions. Biggs [12] analyzed chlorophyll-a (chl-a) and soluble nutrient concentrations in 30 samples from the runoff-affected 
rivers and streams, and found that an increase in nutrients contributed to an increase in chl-a and benthic algae biomass. Qiao et al. [13] analyzed the nutrient and chl-a concentrations in the Bohai Bay, China, during the spring and summer seasons from 1995 to 2013, and identified a negative correlation between dissolved inorganic nitrogen and chl-a concentrations. Furthermore, the researchers concluded that phosphorus limited the growth of phytoplankton during the spring and summer; thus, supporting the indirect relationship between physical parameters and eutrophication. Genkaikato and Carpenter [14] demonstrated that mean depth and temperature strongly influenced the susceptibility of lakes to shifts in dissolved phosphorus and phosphorus in sediments and lake restoration. Jiang et al. [15] and Rixen et al. [16] found that physicochemical parameters, such as temperature, dissolved oxygen, and light, could affect the deposition and release of phosphorus in Taihu Lake by altering microenvironmental conditions, thereby influencing the zooplankton community. Similarly, Xia et al. [17] proposed that climate parameters, including temperature, precipitation, and solar radiation, exacerbated eutrophication events in Chinese lakes.

Chl-a, a basic indicator of phytoplankton abundance, is widely used to represent the presence of algae and primary productivity of phytoplankton in eutrophication models [18-20]. The relationship between chl-a and physical, chemical, and biological properties in lakes, rivers, and reservoirs helps to simplify complex eutrophication studies. Doering et al. [18] evaluated the use of phytoplankton-derived chl-a to estimate eutrophication in the Caloosahatchee Estuary and San Carlos Bay. Zeng et al. [19] used chl-a as an indicator of eutrophication in Chagan Lake, the results of which agreed with eutrophication remotely sensed monitoring data. By studying chl-a as a preliminary indicator of eutrophication in Toyama Bay, Terauchi et al. [20] suggested that a combination of remotely sensed data representing the level and trend of chl-a can be effectively used to assess eutrophication of coastal waters, after a quality screening process with level 2 flags and validation with in situ chl-a data.

Previous research has indicated that eutrophication parameters generally have a non-linear relationship with chl-a concentrations [21-25]. Statistical models, such as principal component analysis (PCA), factor analysis (FA), cluster analysis, and multiple linear regression analysis [26,27], have been used to identify and determine the cause of eutrophication events in a way that single factor analysis cannot achieve [24,28,29]. When studying eutrophication parameters, Wang et al. [30] and Zhao et al. [31] found FA was only able to explain its extraction variables, but could not determine the quantitative relationship. A combination of PCA and radial basis function (RBF) was used by Liu Xiaobo [32] to predict chl-a based on the liner relationship between the main parameters. In summary, FA can identify key variables that explain the original data to the greatest extent. Moreover, PCA can establish a quantitative model for chl-a, and the identify key variables to confirm their degree of influence. Thus, in this study, FA is used in conjunction with PCA to investigate the influence of physicochemical parameters on chl-a, and to determine the quantitative relationship between them.

The Yuqiao Reservoir, which is downstream of the Luan River, is an important industrial, agricultural and domestic water source for the city of Tianjin, China. Since the late 1990s, eutrophication has become problematic in the Yuqiao Reservoir, thus affecting the water quality of Tianjin. Analysis conducted at different locations within the reservoir and during different periods, indicate that the main parameters influencing eutrophication events include chemical oxygen demand (COD), $\mathrm{pH}$, turbidity, temperature (T), dissolved oxygen (DO), and nutrient availability. Most of the eutrophication research conducted at the Yuqiao Reservoir has applied multivariate statistical analyses [31-33]. However, long-term studies addressing the effects of physiochemical parameters on eutrophication events in the reservoir are still required.

Compared to other lakes in China, such as Taihu Lake and Dianchi Lake, the Yuqiao Reservoir has unique characteristics that influence eutrophication. A study investigating eutrophication in Tianchi Lake in the Tianshan Mountains between June and August in 2014 showed that chl-a concentrations ranged from 2.11 to $4.06 \mathrm{mg} / \mathrm{L}$ [34]. Moreover, chl-a concentrations have presented significant negative correlations with water depth and conductivity, while significant positive correlations have been identified with water temperature, $\mathrm{pH}$, and dissolved oxygen concentrations. A study of four Yunnan 
Province plateau lakes, namely Dianchi Lake, Chenghai Lake, Fuxian Lake, and Yi Long Lake, found that nutrient limitation in the four lakes was influenced by pollution sources, watershed area, lake morphology, and hydrodynamic conditions [35].

In this study, chl-a, which is affected by physicochemical parameters, acted as an indicator of algae presence. FA in combination with PCA was applied to identify the key parameters and set up a model to determine the correlation coefficients of chl-a concentrations in water samples collected from the Yuqiao Reservoir (China) between 2003 and 2014. With the ultimate goal of providing recommendations for algal control in the Yuqiao Reservoir, the objectives of this study were to identify variables related to phytoplankton primary productivity and quantify their influence using correlation coefficients.

\section{Research Area}

The Yuqiao Reservoir, an important reservoir in China, serves as the main drinking water source for Tianjin. The reservoir was built in 1959, and became a significant part of the Luanhe-Tianjin water diversion project. It is located $4 \mathrm{~km}$ east of Jixian County $\left(40^{\circ} 02^{\prime} \mathrm{N}, 117^{\circ} 25^{\prime} \mathrm{E}\right)$ north of Tianjin (Figure 1). The valley-type reservoir basin has an average depth of $4.3 \mathrm{~m}$, and a total capacity of 1.559 billion cubic meters. The basin area is approximately 2060 square kilometers. The Sha River, Lin River, and Li River, which make up $1627 \mathrm{~km}^{2}$ of river area, are the main tributaries associated with the reservoir. The watershed is located in a temperate, semi-humid, continental, monsoon climate with an average annual temperature of $10.4-11.5^{\circ} \mathrm{C}$. The average annual precipitation is $748.5 \mathrm{~mm}$, with the rainfall mainly occurring from June to September.

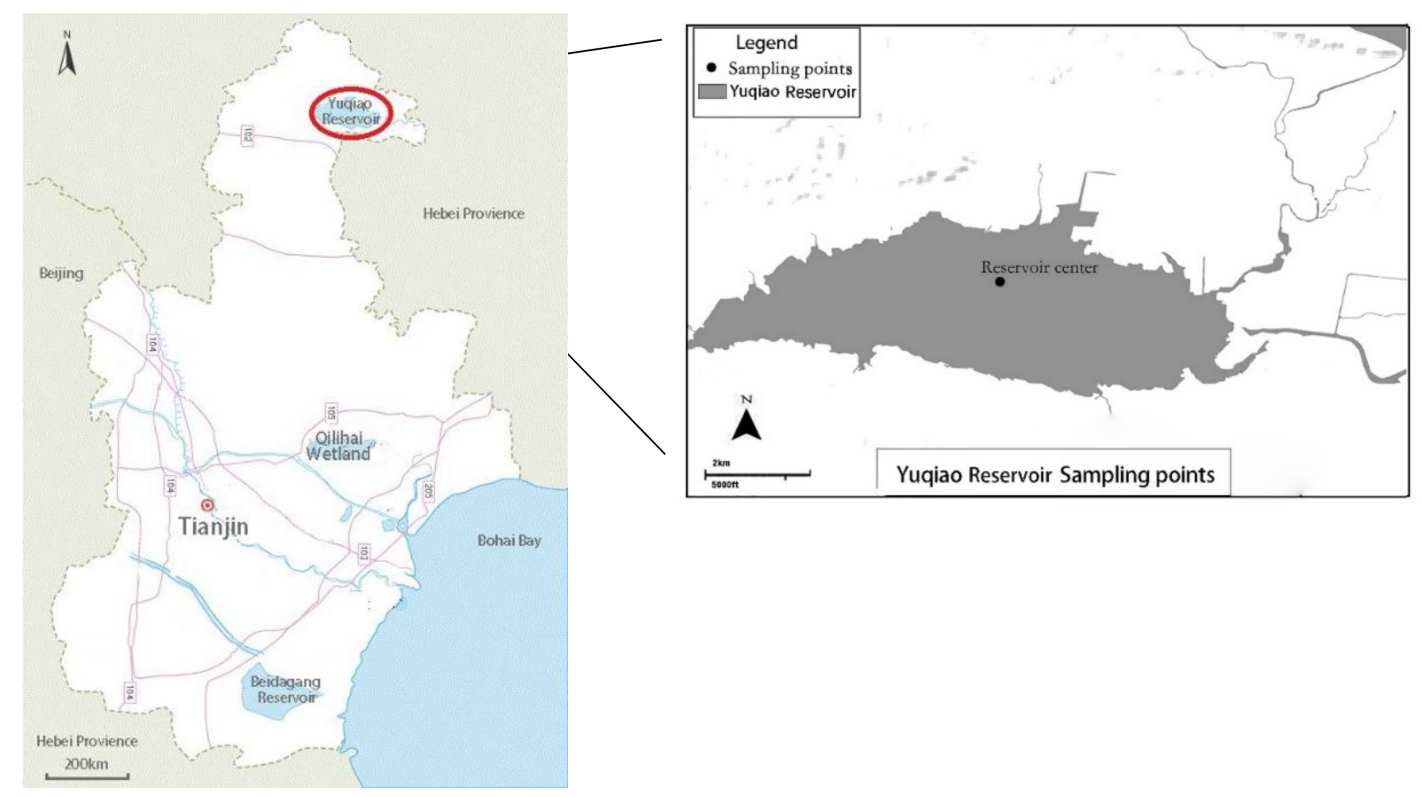

Figure 1. Yuqiao Reservoir location and water distribution monitoring site.

There are 129 villages situated along the reservoir. These villages influence the aquatic ecosystem by introducing sewage and chemical fertilizers into the water through surface runoff from orchards and farmlands. Additionally, pollutants from upstream and surrounding areas cause a continuous input of nitrogen, phosphorus and other nutrients into the reservoir water, thus leading to increasingly problematic eutrophication events [36]. Furthermore, the Yuqiao Reservoir is located in northern China where precipitation is less than in southern parts of the country. Therefore, during periods of water shortage, the concentration of phosphorus tends to increase, which also contributes to algal outbreaks [36,37]. Eutrophication in the Yuqiao Reservoir directly influences drinking water safety in the region, and can be a serious threat to the water quality of Bohai Bay. 
Water samples were collected between 2003 and 2014 from a center monitoring point in the Yuqiao Reservoir (Figure 1). The chl-a concentrations were measured from these samples (Figure 2). The chl-a concentrations decreased from 2003 to 2005, with the lowest in 2005 (approximately $5 \mathrm{mg} / \mathrm{L}$ ). The overall chl-a concentrations were relatively stable (approximately 5-15 mg/L) from 2006 to 2013; however, in 2014, the chl-a levels increased to $12-19 \mathrm{mg} / \mathrm{L}$.

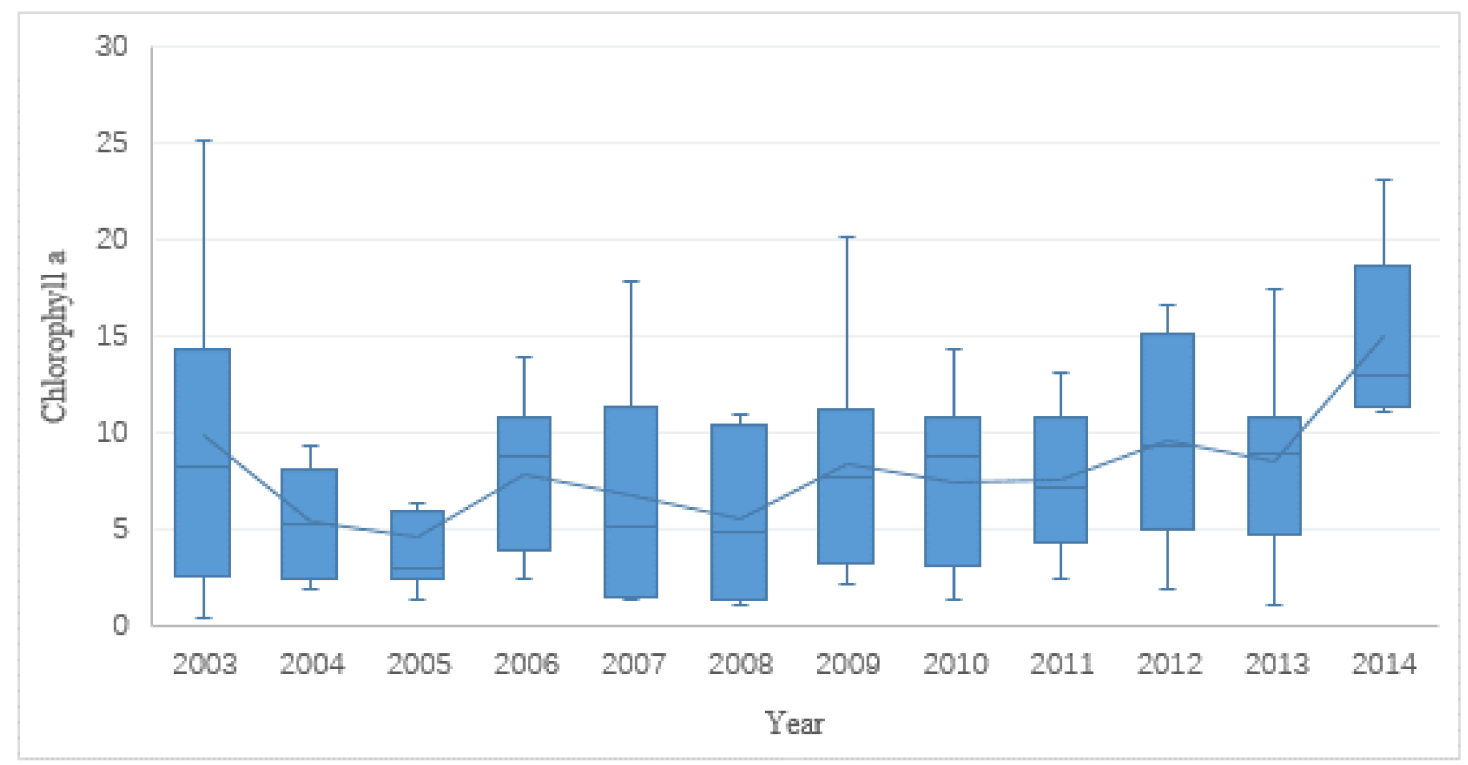

Figure 2. Concentration of chl-a in the center of Yuqiao Reservoir.

\section{Date and Method}

\subsection{Data Selection}

The daily water quality data and chl-a monitoring data used in this study were collected from the Yuqiao Reservoir central monitoring site (Figure 1), which is a national monitoring station of Tianjin Monitoring Center. Parameters used for analysis were temperature ( $\mathrm{T}), \mathrm{pH}$, suspended solids (SS), dissolved oxygen $(\mathrm{DO})$, chemical oxygen demand $\left(\mathrm{COD}_{\mathrm{cr}}\right)$, five-day biochemical oxygen demand $\left(\mathrm{BOD}_{5}\right)$, ammonium $\left(\mathrm{NH}_{4}{ }^{+}\right)$, nitrite $\left(\mathrm{NO}_{2}{ }^{-}\right)$, nitrate $\left(\mathrm{NO}_{3}{ }^{-}\right)$, total nitrogen $(\mathrm{TN})$, and total phosphorus (TP). All monitoring data complied with the national surface water quality standards (No. 838-988, No. 838-002). The samples were collected and analyzed monthly, between March and November, from 2003 to 2014.

\subsection{Research Method}

Data analysis was carried out using SPSS statistics software (version 22) (SPSS China, Shanghai, China). Mapping was completed with Origin (version 9.0). Firstly, the data for the selected physicochemical parameters were pre-treated to eliminate the influence of different units. Secondly, due to the large amount of data, the original data was screened to test outliers by using the Rhine criterion (PanTa) and supplement the data with multiple interpolation methods. Thirdly, PCA was used in conjunction with FA in order to reduce dimensions. PCA determined the main physicochemical parameters affecting chl-a concentrations in the Yuqiao Reservoir, while FA screened out secondary environmental parameters. Finally, the results of the PCA and FA were combined and then used to model the relationship between environmental physicochemical parameters and chl-a in the Yuqiao Reservoir (Figure 3). 


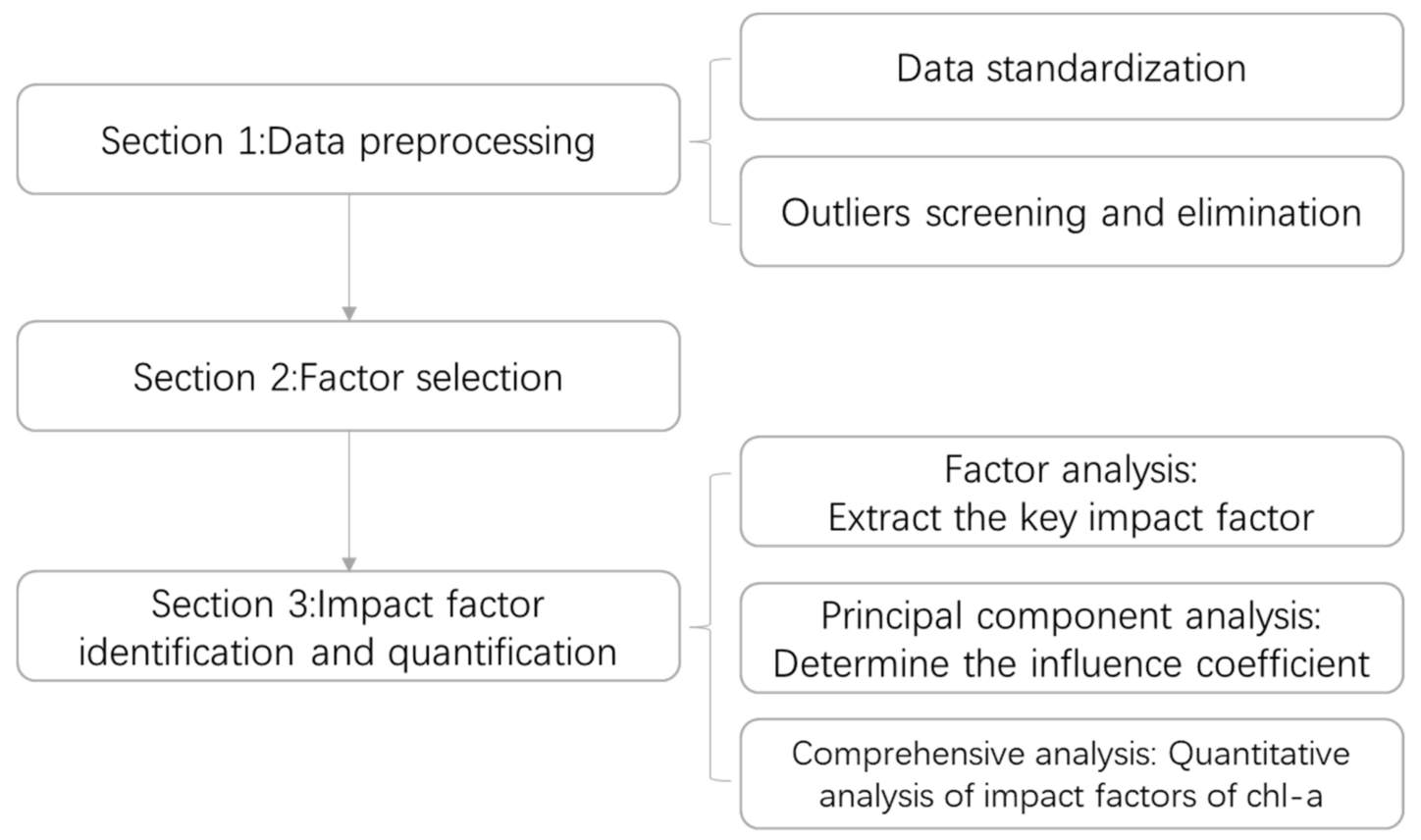

Figure 3. Research method and technical route.

\subsubsection{The Standardization of Data}

Differences in initial variables will seriously affect PCA results. In order to eliminate the different dimensions of error, it is necessary to normalize the data to the same reference system. Thus, the data is treated with matrix $X$. The first step is data standardization using Formula (1).

$$
X_{j}^{k}=\frac{X_{j}-\mu_{j}}{\sqrt{\sigma_{j j}}}
$$

Formula (1) is the standard deviation of the data, where $X_{j}^{k}$ denotes the normalized value of the $j$ th index; $X_{j}$ denotes the actual value of the $j$ th index; $\mu_{j}$ is the average of the $j$ th index; and $\sigma_{j j}$ is the variance of the $j$ th index. After normalizing the original data using this equation, the normalized data variance is 1 , and the average value is zero.

\subsubsection{Screening and Elimination Outliers}

In order to eliminate error caused by the data acquisition process and other disturbances, the standardized data was tested to determine if points should be removed or modified. Due to the large number of measurements, the original data obtained from the Yuqiao Reservoir could be screened and removed using the Rhine criterion. The mean $\bar{X}$ (Formula (2)) and residual error $v_{i}$ (Formula (3)) were obtained using the following data: $X_{1}, X_{2}, X_{3} \ldots X_{n}$. Next, the root-mean-square deviation $\sigma$ (Formula (4)) was calculated. When $\left|X_{i}-\bar{X}\right|>3 \sigma$, the data is considered abnormal and can be discarded. Thus, the original data of the Yuqiao Reservoir was standardized, where the normalized data had a normal distribution with a mean of 0 and a variance of 1 . The extracted data was supplemented with multiple interpolation. Extreme differences in information could be smoothed by exception value processing, thereby helping to arrive at scientific conclusions.

$$
\begin{gathered}
\bar{X}=\frac{1}{n \sum_{i=1}^{n} X_{i}} \\
v_{i}=X_{i}-\bar{X}
\end{gathered}
$$




$$
\sigma=\left(\sum_{i 1}^{n} v_{i}^{2} / n-1\right)^{1 / 2}
$$

\subsubsection{Principal Component Analysis}

PCA, widely used in aquatic environmental and ecological modeling, provides an objective method for working with a large number of biotic and abiotic data. Moreover, PCA simplifies the data and describes a given multidimensional system using a small number of variables. According to Morrison [38], the main component should account for approximately $75 \%$ of the total variance. The relevant component is a parameter with an eigenvalue above 1 [39]. Application of the varimax rotation of the normalized component loading allows us to obtain a clear system by maximizing component load differences and eliminating invalid components [40,41]. Over the years, PCA has been studied separately or in the case of original variables; however, more recently, PCA has been used alone to simulate biological and ecological processes [42].

The model is as follows, with the sample matrix set as (5):

$$
X=\left[\begin{array}{cccc}
x_{11} & x_{12} & \ldots & x_{1 p} \\
x_{21} & x_{22} & \ldots & x_{2 p} \\
\vdots & \vdots & \vdots & \vdots \\
x_{n 1} & x_{n 2} & \ldots & x_{n p}
\end{array}\right]_{n * p}
$$

Matrix (5) is the $n^{*} p$ matrix, where $\mathrm{n}$ is the number of samples and $p$ is the number of variables. $X_{i j}$ is the value of the $j$ th variable in the $i$ th sample.

The principal component analysis of matrix (5) can be combined into $p$ synthesis variables $y_{1}, y_{2}, y_{3} \cdots y_{p}$, as per Formula (6):

$$
\left\{\begin{array}{c}
y_{1}=c_{11} x_{1}+c_{12} x_{2}+\cdots+c_{1 p} x_{p} \\
y_{2}=c_{21} x_{1}+c_{22} x_{2}+\cdots+c_{2 p} x_{p} \\
\cdots \\
\quad \cdots \\
y_{p}=c_{p 1} x_{1}+c_{p 2} x_{2}+\cdots+c_{p p} x_{p}
\end{array}\right.
$$

The relationship exists in (a):

$$
c_{k 1}^{2}+c_{k 2}^{2}+\cdots+c_{k p}^{2}=1(k=1,2,3, \cdots, p)
$$

$y_{1}$ and $y_{2}(i \neq j, i, j=1,2,3 \cdots, p)$ in the formula are independent of each other, which is to say that the correlation is zero. The comprehensive index factor $y_{1}$ satisfies the variance maximum term for all linear combinations of the Formula (6), which is the term of the maximum amount of information representing the original data in the linear combination of Equation (6); $y_{2}$ represents the larger variance, while $\cdots y_{p}$ represents the smallest variance. By using PCA, the comprehensive index factors $y_{1}, y_{2}, y_{3} \cdots y_{p}$ can be obtained. The information of these comprehensive index factors is gradually reduced, which is known as variance of the original variable $1,2,3, \cdots \ldots$, $p$ th main component.

\subsubsection{Factor Analysis}

Factor analysis, first proposed by the British psychologist C.E. Spearman, refers to statistical techniques that extract common factors from variable populations. Furthermore, it can find hidden representative factors among many variables. The same nature of the variables into a factor can reduce the number of variables and test the relationship between variables. The main purpose of factor analysis is to find the correlation coefficient between the factor and the variable. These correlation coefficients constitute the factor structure, whereas the correlation coefficient between the variables is used to determine the factor load. Variance maximization rotation, promax oblique rotation and 
other methods can be applied to clarify the meaning of the linear regression, so as to achieve the linear combination of coefficients and determine the practical significance of each factor.

The model is as follows: normalize the matrix as matrix $X$. The covariance matrix $R$ expression is as follows:

$$
R=X^{\prime} \cdot X
$$

The vector matrix is (9), and $U U^{\prime}=I$.

$$
R=U\left[\begin{array}{cccc}
\lambda_{1} & & & 0 \\
& \lambda_{2} & & \\
& & \ddots & \\
0 & & & \lambda_{n}
\end{array}\right] U^{\prime}
$$

Let

$$
F=U^{\prime} X,
$$

where $F$ is the principal factor matrix; and $F_{\alpha}(\alpha=1,2,3 \cdots, p)$ is the observed principal factor value of the $\alpha$ th sample. According to the standard selection of $m(m<n)$ main factors, the $U$ matrix can be divided into

$$
U=\left[U_{1} U_{2} \cdots U_{m} U_{m+1} \cdots U_{n}\right]
$$

Next, multiply $U$ to the Formula (10):

$$
X=U_{(1)} F_{(1)}+U_{(2)} F_{(2)}
$$

The term $U_{(1)} F_{(1)}$ is the residual part, which is negligible. After omitting the residual part, the factor model is obtained:

$$
X=U_{(1)} F_{(1)}
$$

$U_{(1)}$ is the factor load matrix, and $F_{(1)}$ is the main factor matrix.

$$
\left\{\begin{array}{r}
x_{1}=u_{11} F_{1}+u_{12} F_{2}+\cdots+u_{1 m} F_{m} \\
x_{2}=u_{21} F_{1}+u_{22} F_{2}+\cdots+u_{2 m} F_{m} \\
\cdots \\
\cdots \\
x_{n}=u_{n 1} F_{1}+u_{n 2} F_{2}+\cdots+u_{n m} F_{m}
\end{array}\right.
$$

Finally, the factor load matrix and the $R$-factor model are obtained by normalizing $u_{i j}$ in (14).

In the PCA and FA calculation, only second-order characteristics of the probability density distribution function of input data are involved, they do not satisfy the independent conditions. However, most of the important features of the input signal are often included in the higher-order statistics that satisfy the degree of freedom; therefore, this approach only works if multivariate observations are made from source signals with a Gaussian distribution. The Kaiser-Meyer-Olkin $(\mathrm{KMO})$ statistical test, with an index ranging from 0 to 1 , is used to compare the simple correlation coefficient and the partial correlation coefficient between variables. When the square sum of the simple correlation coefficient between all the variables is far greater than the square of the partial correlation coefficient, the KMO value is close to 1, thereby indicating that the correlation between the variables is stronger. Bartlett's spherical test is used to test the correlation between variables in the matrix to determine if they are independent. Additionally, it determines if the correlation matrix is an identity matrix, and if the independent factor analysis of each variable is invalid. SPSS test results showed $p<0.05$, indicating that there is a correlation between the variables. If the KMO test and Bartlett's spherical test can determine that the data follow a Gaussian distribution, then PCA and FA are deemed applicable. 
Based on the introduction and description of PCA and FA, the PCA-based model obtained by the variance accumulation and variables extracted by FA. The combination of PCA and FA is used to determine the intrinsic relationship between chl-a and other physical and chemical parameters, in order to explain the meaning of the extracted influencing variables and to illustrate the extent of them.

\section{Results}

\subsection{Factor Selection}

Pearson correlation analysis was performed on the samples after eliminating the outliers by multiple interpolation. The results are shown in Table 1.

Results show that chlorophyll-a does not have a significant correlation with $\mathrm{BOD}_{5}$, nitrate, and $\mathrm{TN}$ (Table 1), indicating that these physicochemical parameters likely have little influence on algal growth. Therefore, FA and PCA was performed on the normalized data of T, $\mathrm{pH}, \mathrm{DO}, \mathrm{SS}, \mathrm{COD}_{\mathrm{Cr}}$, ammonium, nitrite, TP, and the nitrogen-phosphorus ratio.

\subsection{Identification and Quantification of Key Physicochemical Parameters}

The results of the KMO and Bartlett sphericity tests and factor extraction are shown in Tables 2 and 3. According to the result of the KMO test, which was 0.623 , the correlation between the data samples was good. In addition, the results of the factor extraction were greater than 0.5 , meaning that the interpretation of environmental factors was high. Thus, the sample was suitable for factor analysis.

The correlation coefficient matrix was used to solve the eigenvalues. Four physicochemical parameters were extracted according to the principle that the eigenvalues are more than 1 , and the cumulative explanatory degree is $71.097 \%$ (Table 4 ). Therefore, the variables used for analysis were reduced from 12 to 4 .

According to the rotation element matrix and the factor loading plot (Figure 4), the physicochemical parameters (temperature, $\mathrm{DO}, \mathrm{TP}, \mathrm{COD}_{\mathrm{Cr}}, \mathrm{NO}_{2}{ }^{-}, \mathrm{NH}_{4}{ }^{+}$) circled in Figure 4 can be categorized into four explanatory variables. The first factor represents total phosphorus and the nitrogen-phosphorus ratio; therefore, the first factor is referred to as the phosphorus control variable. The second factor represents $\mathrm{T}$ and $\mathrm{DO}$, which is referred to as the physical environmental variable. The third factor is primarily explained by $\mathrm{COD}_{\mathrm{Cr}}$, while the fourth factor is mainly explained by ammonium and nitrite; therefore, the fourth factor is referred to as the nitrogen control variable.
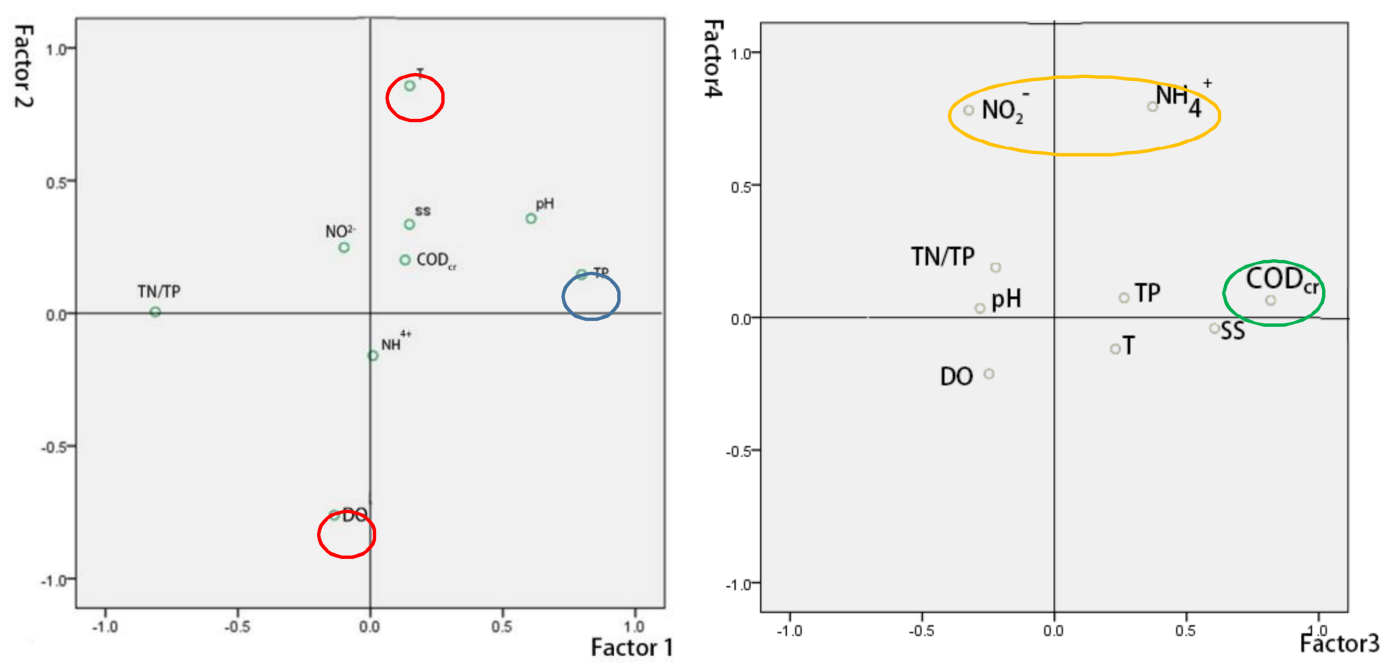

Figure 4. Factor loading plot. 
Table 1. Correlation coefficients between target physicochemical parameters and chlorophyll-a concentrations.

\begin{tabular}{|c|c|c|c|c|c|c|c|c|c|c|c|c|c|}
\hline Coefficient & $T$ & $\mathrm{pH}$ & SS & DO & $\mathrm{COD}_{\mathrm{cr}}$ & BOD $_{5}$ & $\mathrm{NH}_{4}{ }^{+}$ & $\mathrm{NO}_{2}^{-}$ & $\mathrm{NO}_{3}{ }^{-}$ & TN & TP & $\mathrm{N} / \mathrm{P}$ & Chl-a \\
\hline $\mathrm{T}$ & 1 & $0.272 * *$ & $0.351 * *$ & $-0.631^{* *}$ & $0.326^{* *}$ & 0.162 & -0.038 & -0.016 & -0.184 & -0.144 & $0.284^{* *}$ & $-0.241^{*}$ & $0.501^{* *}$ \\
\hline $\mathrm{pH}$ & 0.272 ** & 1 & 0.202 & -0.118 & 0.056 & -0.145 & -0.061 & 0.069 & 0.079 & 0.060 & $0.296^{* *}$ & $-0.247^{*}$ & $0.248 *$ \\
\hline SS & $0.351 * *$ & 0.202 & 1 & $-0.231 *$ & $0.467^{* *}$ & 0.041 & 0.082 & -0.041 & $-0.298^{* *}$ & -0.208 * & 0.239 * & $-0.213 *$ & $0.412 * *$ \\
\hline DO & $-0.631^{* *}$ & -0.118 & $-0.231 *$ & 1 & $-0.310^{* *}$ & -0.122 & -0.165 & -0.166 & 0.189 & 0.118 & $-0.345^{* *}$ & 0.206 * & $-0.485^{* *}$ \\
\hline $\mathrm{COD}_{\mathrm{cr}}$ & $0.326^{* *}$ & 0.056 & $0.467^{* *}$ & $-0.310^{* *}$ & 1 & 0.181 & $0.214^{*}$ & -0.108 & $-0.305^{* *}$ & $-0.241 *$ & $0.354^{* *}$ & -0.185 & $0.431^{* *}$ \\
\hline $\mathrm{BOD}_{5}$ & 0.162 & -0.145 & 0.041 & -0.122 & 0.181 & 1 & 0.077 & -0.058 & 0.026 & 0.080 & -0.049 & 0.103 & 0.095 \\
\hline $\mathrm{NH}_{4}^{+}$ & -0.038 & -0.061 & 0.082 & -0.165 & 0.214 * & 0.077 & 1 & $0.281^{* *}$ & 0.144 & 0.133 & 0.043 & 0.032 & $0.291^{* *}$ \\
\hline $\mathrm{NO}_{2}^{-}$ & -0.016 & 0.069 & -0.041 & -0.166 & -0.108 & -0.058 & $0.281^{* *}$ & 1 & $0.507^{* *}$ & $0.506^{* *}$ & -0.037 & 0.258 * & $0.208^{*}$ \\
\hline $\mathrm{NO}_{3}^{-}$ & -0.184 & 0.079 & $-0.298^{* *}$ & 0.189 & $-0.305^{* *}$ & 0.026 & 0.144 & $0.507 * *$ & 1 & $0.902 * *$ & -0.188 & $0.517 * *$ & -0.157 \\
\hline $\mathrm{TP}$ & $0.284^{* *}$ & $0.296^{* *}$ & $0.239 *$ & $-0.345^{* *}$ & $0.354^{* *}$ & -0.049 & 0.043 & -0.037 & -0.188 & -0.068 & 1 & $-0.568^{* *}$ & $0.478^{* *}$ \\
\hline $\mathrm{N} / \mathrm{P}$ & $-0.241 *$ & $-0.247^{*}$ & -0.213 * & $0.206^{*}$ & -0.185 & 0.103 & 0.032 & 0.258 * & $0.517^{* *}$ & $0.519 * *$ & $-0.568 * *$ & 1 & $-0.220 *$ \\
\hline chl-a & $0.501^{* *}$ & $0.248 *$ & $0.412^{* *}$ & $-0.485^{* *}$ & $0.431^{* *}$ & 0.095 & $0.291^{* *}$ & $0.208 *$ & -0.157 & -0.032 & $0.478^{* *}$ & $-0.220^{*}$ & 1 \\
\hline
\end{tabular}

${ }^{* *}$ Indicates that the correlation is significant at $p<0.01$ level; ${ }^{*}$ indicates that the correlation is significant at $p<0.05$ level. 
Table 2. KMO and Bartlett sphericity tests.

\begin{tabular}{cc}
\hline Kaiser-Meyer-Olkin & \\
Measuring Sampling Adequacy & $\mathbf{0 . 6 2 3}$ \\
\hline Sphere calibration of Bartlett & 192.999 \\
Df & 36 \\
Significance & 0.000 \\
\hline
\end{tabular}

Table 3. Accumulated extraction of target parameters.

\begin{tabular}{ccc}
\hline \multicolumn{3}{c}{ Communalities } \\
\hline & Origin & Extract \\
\hline $\mathrm{T}$ & 1.000 & 0.825 \\
$\mathrm{pH}$ & 1.000 & 0.576 \\
$\mathrm{SS}$ & 1.000 & 0.503 \\
$\mathrm{DO}$ & 1.000 & 0.704 \\
$\mathrm{COD}$ & 1.000 & 0.732 \\
$\mathrm{NH}_{4}{ }^{+}$ & 1.000 & 0.796 \\
$\mathrm{NO}_{2}{ }^{-}$ & 1.000 & 0.787 \\
$\mathrm{TP}$ & 1.000 & 0.732 \\
$\mathrm{~N} / \mathrm{P}$ & 1.000 & 0.744 \\
\hline
\end{tabular}

Table 4. Eigenvalues and cumulative variance.

\begin{tabular}{cccc}
\hline \multirow{2}{*}{ Factor } & \multicolumn{3}{c}{ Characteristic Value } \\
\cline { 2 - 4 } & Total & Variation \% & Accumulation \% \\
\hline 1 & 2.810 & 31.219 & 31.219 \\
2 & 1.473 & 16.361 & 47.580 \\
3 & 1.112 & 12.359 & 59.939 \\
4 & 1.004 & 11.158 & 71.097 \\
5 & 0.876 & 9.734 & 80.832 \\
6 & 0.583 & 6.478 & 87.310 \\
7 & 0.523 & 5.817 & 93.127 \\
8 & 0.332 & 3.687 & 96.813 \\
9 & 0.287 & 3.187 & 100.000 \\
\hline
\end{tabular}

The eigenvector corresponding to the eigenvalue is rotated according to the maximum variation method of Kaiser normalization. The relationship between the extracted variables and the environmental parameters is as follows:

$$
\begin{aligned}
& \mathrm{Z} 1=-0.122 \mathrm{X}_{(\mathrm{T})}+0.398 \mathrm{X}_{(\mathrm{pH})}-0.068 \mathrm{X}_{(\mathrm{SS})}+0.081 \mathrm{X}_{(\mathrm{DO})}-0.075 \mathrm{X}_{(\mathrm{CODCr})}+0.057 \mathrm{X}_{(\mathrm{NH} 4}{ }^{+}{ }^{+}+ \\
& \left.0.008 \mathrm{X}_{(\mathrm{NO} 2}{ }^{-}\right)+0.491 \mathrm{X}_{(\mathrm{TP})}-0.513 \mathrm{X}_{(\mathrm{N} / \mathrm{P})} \text {; } \\
& \mathrm{Z} 2=0.563 \mathrm{X}_{(\mathrm{T})}+0.182 \mathrm{X}_{(\mathrm{pH})}+0.108 \mathrm{X}_{(\mathrm{SS})}-0.461 \mathrm{X}_{(\mathrm{DO})}-0.035 \mathrm{X}_{(\mathrm{CODCr})}-0.259 \mathrm{X}_{(\mathrm{NH} 4}{ }^{+}{ }^{+}+ \\
& 0.187 \mathrm{X}_{\left(\mathrm{NO}^{-}{ }^{-}\right)}-0.113 \mathrm{X}_{(\mathrm{TP})}+0.194 \mathrm{X}_{(\mathrm{N} / \mathrm{P})} \text {; } \\
& \mathrm{Z} 3=-0.003 \mathrm{X}_{(\mathrm{T})}-0.372 \mathrm{X}_{(\mathrm{pH})}+0.368 \mathrm{X}_{(\mathrm{SS})}-0.018 \mathrm{X}_{(\mathrm{DO})}+0.550 \mathrm{X}_{(\mathrm{CODCr})}+0.280 \mathrm{X}_{(\mathrm{NH} 4}{ }^{+}{ }^{-}- \\
& 0.293 \mathrm{X}_{\left(\mathrm{NO}^{-}{ }^{-}\right)}+0.040 \mathrm{X}_{(\mathrm{TP})}-0.042 \mathrm{X}_{(\mathrm{N} / \mathrm{P})} \text {; } \\
& \left.\mathrm{Z} 4=-0.162 \mathrm{X}_{(\mathrm{T})}+0.061 \mathrm{X}_{(\mathrm{pH})}-0.066 \mathrm{X}_{(\mathrm{SS})}-0.098 \mathrm{X}_{(\mathrm{DO})}+0.019 \mathrm{X}_{(\mathrm{CODCr})}+0.610 \mathrm{X}_{(\mathrm{NH} 4}{ }^{+}\right)+ \\
& 0.572 \mathrm{X}_{\left(\mathrm{NO}^{-}{ }^{-}\right)}+0.113 \mathrm{X}_{(\mathrm{TP})}+0.071 \mathrm{X}_{(\mathrm{N} / \mathrm{P})} \text {; }
\end{aligned}
$$


The extracted Z1, Z2, Z3, Z4, and chl-a were analyzed by regression analysis to determine the correlation coefficient of the extracted factor on chl-a. The simulation results are as follows: Chl-a $=0.977 \mathrm{X} 1+1.983 \mathrm{X} 2+1.797 \mathrm{X} 3+1.595 \mathrm{X} 4+7.963, R^{2}=0.504$.

The results show that there were four physicochemical parameters affecting chlorophyll levels in the Yuqiao Reservoir between 2003 and 2014, namely, the phosphorus control variable, the physical environmental variable, $\mathrm{COD}_{\mathrm{Cr}}$, and the nitrogen control variable. The correlation coefficients were $0.977,1.983,1.797$, and 1.595 . Comparing the above four factors with the eigenvectors of the environmental physicochemical parameters, the influence coefficients of T, $\mathrm{pH}, \mathrm{SS}, \mathrm{DO}, \mathrm{COD}_{\mathrm{Cr}}, \mathrm{TP}$, and nitrogen-phosphorus ratio on chlorophyll-a were $0.733,0.179,0.704,-1.024,0.876,1.018,0.764$, 0.508 , and -0.079 , respectively. The relationship between nitrogen and nitrogen-phosphorus ratio was negatively correlated with chl-a, while the other environmental physicochemical parameters were positively correlated with chl-a.

\section{Discussion}

The main environmental parameters that affected chl-a concentrations in the Yuqiao Reservoir between 2003 and 2014 were phosphorus, physical parameters (mainly $\mathrm{T}$ and $\mathrm{DO}$ ), $\mathrm{COD}_{\mathrm{Cr}}$, and nitrogen. The $R^{2}$ of the PCA was greater than 0.5 , so the result is valid. These results can be compared to previously published literature that assessed physicochemical parameters influencing chl-a concentrations in the Yuqiao Reservoir. For example, Liu et al. [32] studied the relationship between environmental physicochemical parameters and chl-a concentrations in the Yuqiao Reservoir from 2003 to 2005, and found that T, COD, and $\mathrm{NH}_{4}{ }^{+}$had the most influence on chl-a concentrations. Furthermore, phosphorus was found to significantly affect chl-a concentrations in the Yuqiao Reservoir, which is consistent with the conclusion that the Yuqiao Reservoir has been gradually transformed into a phosphorus-controlled environment [43]. Therefore, it is necessary to study the sources of phosphorus and control measures for pollution sources. Zhao and Cui [31] found that turbidity, chl-a, alkalinity, and hardness were the main parameters influencing seasonal variability of water ecosystems in northern China. Liu et al. [43] suggested that air pressure and $\mathrm{pH}$ were the main parameters affecting chl-a levels in a study conducted between 1999 and 2012. Thus, the choice of environmental parameters will have an impact on the results, depending on the period and seasons of study. Different nitrogen and phosphorus concentrations influence the characteristics of algal populations [8]. The use of nitrogen-phosphorus ratios is increasingly utilized in water quality research. Although the Yuqiao Reservoir is a phosphorus-controlled reservoir, the results show that the effects of nitrogen cannot be ignored $[30,33,37]$. According to the results, there is another difference about the phosphorus impact parameter and the nitrogen influencing variable among the previous research on the eutrophication of the Yuqiao Reservoir. It has been shown that the roles of nitrogen and phosphorus in eutrophication events are complex. Utilization of different phosphorus and nitrogen compounds by phytoplankton is a complex process that involves more than a single nutrient; thus, these parameters play an important role in chl-a levels.

Nutrients are the most important physicochemical parameter affecting chlorophyll-a concentrations in the Yuqiao Reservoir. The phosphorus control variable acts as the first influencing factor, which agrees with the research of Li et al. [43] and other research indicating that the Yuqiao Reservoir is phosphorus controlled. The nitrogen-phosphorus ratio is negatively correlated with chl-a concentrations, and it is helpful to show that the effect of phosphorus is higher than that of nitrogen. Research on Yuqiao Reservoir pollution sources have mostly focused on non-point source pollution of nutrients in the periphery of the reservoir. Studies have shown that agricultural runoff and livestock farming is mainly responsible for the non-point source nitrogen and phosphorus pollution load from the area surrounding reservoir [44-47]. First, the residents are mainly engaged in agricultural cultivation and fishing. As such, the resulting domestic sewage, livestock manure, solid waste, pesticides, and fertilizers are discharged directly into the reservoir or enter through the surface runoff [48]. Hence, regulating agricultural activities is the most significant method for controlling 
nitrogen and phosphorus input into the reservoir. Additionally, the influence of sediments in the Yuqiao Reservoir, which are also an important source of nutrients and organic matter, has received little attention. Wu et al. [49] studied the surface sediments of the Yuqiao Reservoir, and showed that the ratio of available phosphorus to total phosphorus took accounted for the largest proportion, indicating that endogenous phosphorus release is prominent. Hao-ping et al. [50] showed that sediment-associated nutrients and their release was related to the type of land use surrounding the Yuqiao Reservoir. Moreover, by analyzing the water quality of the reservoir from 2000 to 2010, Xie et al. [45] concluded that ammonium and total phosphorus in sediments were characterized by poor biodegradability and seasonal fluctuation, and ultimately had the largest contribution to eutrophication events. In order to control the contribution of nutrients into the Yuqiao Reservoir, further endogenous studies need to be conducted.

The physical environmental parameters affecting chl-a levels in the reservoir are $\mathrm{T}, \mathrm{DO}$, and $\mathrm{COD}_{\mathrm{cr}}$. Temperature positively correlates with chl-a, which is consistent with the growth of algae in the summer, when the temperature is higher $[17,45,51]$. It is speculated that at different temperatures, the environmental physicochemical parameters that affect chl-a concentrations in the reservoir are different. Because DO has a negative correlation with chl-a, mechanical and chemical reagents could be used to increase the dissolved oxygen content of the Yuqiao Reservoir, thereby reducing chl-a levels. Physical parameters also have an impact on endogenous nutrients, which indirectly affect chl-a concentrations [37,43,51]. A study from Cong et al. [52] showed that low DO and high $\mathrm{pH}$ have a synergistic effect on the release of phosphorus in sediments, and that the release of nitrogen is mainly affected by DO. Furthermore, $C_{C D}$ cr represents the content of organic matter in water. High degrees of eutrophication can provide ideal growth conditions for some aquatic plants, such as Potamogeton crispus; however, this will increase necrotic organic matter, which subsequently consumes a large portion of the DO [33,37,51]. Therefore, an effective eutrophication control measure is the timely cleanup of floating plants and animals in the Yuqiao Reservoir.

In this study, we used a combination of FA and PCA to explore the relationship between chl-a and its influencing physicochemical parameters in the Yuqiao Reservoir. This approach reduced the potential environmental variables from 12 to 4 , which greatly reduced the repetition of the physicochemical parameters. Furthermore, a linear model between chl-a concentrations and the physicochemical parameters was established, which provided a reliable basis for eutrophication management in the center of the Yuqiao Reservoir. As demonstrated by previous studies, independent application of the FA method can extract key physicochemical parameters while properly explaining eutrophication; however, quantitative analysis is not possible. Conversely, PCA can identify the influencing parameters but cannot explain their meaning [30,32,42]. Duan et al. [53] applied PCA/FA to study Poyang Lake; however, this study only extracted the main influencing physicochemical parameters, and did not built a quantitative model. In this study, the combination of FA and PCA overcame the above shortfalls. The respective advantages of the two methods was exploited, and the statistical dimension was reduced to simplify the analysis.

\section{Conclusions}

In this study, FA in conjunction with PCA was utilized to study the relationship between chl-a, a representative index of algae in aquatic ecosystems, and its associated physicochemical parameters and nutrients. Yuqiao Reservoir, acting as a significant drinking water source for Tianjin in northern China, has been seriously affected by eutrophication. Daily monitoring data of the physicochemical parameters and chl-a concentrations from 2003 to 2014 was studied. Quantitative analysis of chl-a concentrations and the environmental physicochemical parameters indicates that the main environmental parameters influencing chl-a levels are the phosphorus control variable, the physical environmental variable, $\mathrm{COD}_{\mathrm{cr}}$, and the nitrogen control variable. Furthermore, chl-a was negatively correlated with DO, nitrogen, and phosphorus, while other physicochemical parameters were positively correlated with chl-a. 
Control of nutrients, DO, and organic matter content can prevent algal outbreaks, which result in elevated chl-a concentrations. Agricultural activities are important pollution sources in the Yuqiao Reservoir. Compared to studies in other lakes, the Yuqiao Reservoir is unique, making it necessary to carry out separate analysis of this ecosystem. Furthermore, to ensure safety of the drinking water source, water quality management should be stringent and suitable to the specific needs of the reservoir.

In addition to identifying and quantifying the parameters affecting chl-a concentrations, the combined FA/PCA method solves important problems, namely, that the actual meaning of the PCA extraction variable is unknown, and that the extracted variable of FA cannot be quantified. However, because the environmental physicochemical parameters are not completely extracted, this model can be improved. Moreover, follow-up studies should investigate seasonal variation to clarify the relationship between chl-a concentrations and environmental physicochemical parameters in the Yuqiao reservoir at different temperatures.

Acknowledgments: This study was supported by Water Pollution Emission Inventory Establishment and Forecasting and Warning System Construction of Luan river-Tianjin Water Diversion Project and Study on Carrying Capacity of Ecosystem Protection and Green Development of Lvshui Watershed and Yuetan Reservoir (HZCG2017Z159). The authors would also like to thank the editors and anonymous reviewers for their insightful comments and suggestions.

Author Contributions: Chunli Chu conceived and designed the framework; Ran Chen, Weiqiang Jing and Yuqiu Wang analyzed the data; Tong Li wrote the paper; Chunli Chu and Meiting Ju contributed to improving the article.

Conflicts of Interest: The authors declare no conflict of interest.

\section{References}

1. Schindler, D.W. Eutrophication and recovery in experimental lakes: Implications for lake management. Science 1974, 184, 897-899. [CrossRef] [PubMed]

2. Carpenter, S.R.; Ludwig, D.; Brock, W.A. Management of eutrophication for lakes subject to potentially irreversible change. Ecol. Appl. 1998, 9, 751-771. [CrossRef]

3. Smith, V.H. Eutrophication of freshwater and coastal marine ecosystems: A global problem. Environ. Sci. Pollut. Res. Int. 2003, 10, 126. [CrossRef] [PubMed]

4. Conley, D.J.; Paerl, H.W.; Howarth, R.W.; Boesch, D.F.; Seitzinger, S.P.; Havens, K.E.; Lancelot, C.; Gene, E.; Likens, G.E. Controlling eutrophication: Nitrogen and phosphorus. Science 2009, 323, 1014. [CrossRef] [PubMed]

5. Pant, M.C.; Sharma, A.P.; Sharma, P.C. Evidence for the increased eutrophication of lake Nainital as a result of human interference. Environ. Pollut. 1980, 1, 149-161. [CrossRef]

6. Paerl, H.W. Controlling Eutrophication along the Freshwater-Marine Continuum: Dual Nutrient (N and P) Reductions are Essential. Estuar. Coasts 2009, 32, 593-601. [CrossRef]

7. Carpenter, S.R.; Bennett, E.M. Reconsideration of the planetary boundary for phosphorus. Environ. Res. Lett. 2011, 6, 14009-14020. [CrossRef]

8. Anderson, D.M.; Glibert, P.M.; Burkholder, J.M. Harmful algal blooms and eutrophication: Nutrient sources, composition, and consequences. Estuaries 2002, 25, 704-726. [CrossRef]

9. Howarth, R.W.; Marino, R. Nitrogen as the limiting nutrient for eutrophication in coastal marine ecosystems: Evolving views over three decades. Limnol. Oceanogr. 2006, 51, 364-376. [CrossRef]

10. Fisher, T.R.; Melack, J.M.; Grobbelaar, J.U.; Howarth, R.W. Phosphorus in the global environment. In Nutrient Limitation of Phytoplankton and Eutrophication of Inland, Estuarine and Marine Waters; Wiley and Sons: Chichester, UK, 1995.

11. Nixon, S.W. Coastal marine eutrophication: A definition, social causes, and future concerns. Ophelia 1995, 41, 199-219. [CrossRef]

12. Biggs, B.J.F. Eutrophication of streams and rivers: Dissolved nutrient-chlorophyll relationships for benthic algae. J. N. Am. Benthol. Soc. 2000, 19, 17-31. [CrossRef]

13. Qiao, Y.; Feng, J.; Cui, S.; Zhu, L. Long-term changes in nutrients, chlorophyll a and their relationships in a semi-enclosed eutrophic ecosystem, Bohai Bay, China. Mar. Pollut. Bull. 2017, 117, 222. [CrossRef] [PubMed] 
14. Genkaikato, M.; Carpenter, S.R. Eutrophication due to phosphorus recycling in relation to Lake Morphometry, temperature and macrophysics. Ecology 2005, 86, 210-219. [CrossRef]

15. Jiang, X.; Jin, X.; Yang, Y.; Li, L.; Wu, F. Effects of biological activity, light, temperature and oxygen on phosphorus release processes at the sediment and water interface of Taihu Lake, China. Water Res. 2008, 42, 2251-2259. [CrossRef] [PubMed]

16. Rixen, T.; Baum, A.; Sepryani, H.; Pohlmann, T.; Jose, C.; Samiaji, J. Dissolved oxygen and its response to eutrophication in a tropical black water river. J. Environ. Manag. 2010, 91, 1730-1737. [CrossRef] [PubMed]

17. Xia, R.; Zhang, Y.; Critto, A.; Wu, J.; Fan, J.; Zheng, Z.; Zhang, Y. The Potential Impacts of Climate Change Factors on Freshwater Eutrophication: Implications for Research and Countermeasures of Water Management in China. Sustainability 2007, 8, 229. [CrossRef]

18. Doering, P.H.; Chamberlain, R.H.; Haunert, K.M. Chlorophyll A and its use as an indicator of eutrophication in the Caloosahatchee Estuary. Fla. Sci. 2006, 69, 51-72.

19. Zeng, N.; Liu, Z.; Miao, Z.; Wei, Y. Design and Implementation of Chlorophyll a and Eutrophication Remote Sensing Monitoring System Based on ArcGIS Engine. In Proceedings of the 2008 International Workshop on Education Technology and Training \& 2008 International Workshop on Geoscience and Remote Sensing, Shanghai, China, 21-22 December 2008; pp. 840-843.

20. Terauchi, G.; Tsujimoto, R.; Ishizaka, J.; Nakata, H. Preliminary assessment of eutrophication by remotely sensed chlorophyll-a, in Toyama Bay, the Sea of Japan. J. Oceanogr. 2014, 70, 175-184. [CrossRef]

21. Tongeren, O.F.R.V.; Liere, L.V.; Gulati, R.D.; Postema, G.; Boesewinkel-De Bruyn, P.J. Multivariate analysis of the plankton communities in the Loosdrecht lakes: Relationship with the chemical and physical environment. Hydrobiologia 1992, 233, 105-117. [CrossRef]

22. Romo, S.; Donk, E.V.; Gylstra, R.; Gulati, R. A multivariate analysis of phytoplankton and food web changes in a shallow biomanipulated lake. Freshw. Biol. 2010, 36, 683-696. [CrossRef]

23. Zheng, Y.; Wang, X.J.; Jiang, Y.C.; Zhou, X.W. Analysis on water quality of rivers around Tai Lake and estimation of total pollutant load into Tai Lake. Geogr. Territ. Res. 2001, 17, 40-44.

24. Arhonditsis, G.B.; Winder, M.; Brett, M.T.; Schindler, D.E. Patterns and mechanisms of phytoplankton variability in Lake Washington (USA). Water Res. 2004, 38, 4013-4027. [CrossRef] [PubMed]

25. Thomas, G.; Eckmann, R. The influence of eutrophication and population biomass on common white. Can. J. Fish. Aquat. Sci. 2007, 64, 402-410. [CrossRef]

26. Cacho, O.J. Systems modelling and bioeconomic modelling in aquaculture. Aquac. Econ. Manag. 1997, 1, 45-64. [CrossRef]

27. Tufford, D.L.; Mckellar, H.N. Spatial and temporal hydrodynamic and water quality modeling analysis of a large reservoir on the South Carolina (USA) coastal plain. Ecol. Model. 1999, 114, 137-173. [CrossRef]

28. Momen, B.; Eichler, L.W.; Boylen, C.W.; Zehr, J.P. Application of multivariate statistics in detecting temporal and spatial patterns of water chemistry in Lake George, New York. Ecol. Model. 1996, 91, 183-192. [CrossRef]

29. Lau, S.S.; Lane, S.N. Biological and chemical factors influencing shallow lake eutrophication: A long-term study. Sci. Total Environ. 2002, 288, 167. [CrossRef]

30. Wang, X.H.; Yin, C.Q.; Shan, B.Q. Control of diffuse P-pollutants by multiple buffer/detention structures by Yuqiao Reservoir, North China. J. Environ. Sci. 2004, 16, 616-620.

31. Zhao, Z.W.; Cui, F.Y. Multivariate statistical analysis for the surface water quality of the Luan River, China. J. Zhejiang Univ. 2009, 10, 142-148. [CrossRef]

32. Liu, X.; Dong, F.; He, G.; Liu, J. Use of PCA-RBF model for prediction of chlorophyll-a in Yuqiao Reservoir in the Haihe River Basin, China. Water Sci. Technol. Water Supply 2014, 14, 73.

33. Liu, X.; Nie, Y.; Zhao, X.; Liu, Q. A Correlation Analysis of the Phytoplankton Community and Environment Factors in the Yuqiao Reservoir in Spring and Summer of 2014. Environ. Monit. China 2016, 32, 64-68.

34. Wang, B.; Ma, J.; Wang, Y.Y.; Yin, X.J. Distribution of Chlorophyll-a and Eutrophication State in Tianchi Lake of Tianshan Mountains in Summer. Huanjing Kexue 2015, 36, 2465. [PubMed]

35. Li, Y.; Yan, X.; Wu, Z.; He, B. Quantitative relationship between chlorophyll a and key controlling factors in Four Plateau Lakes in Yunnan Province, China. Huanjing Kexue Xuebao 2015, 35, 402-410.

36. Wu, D.; Wang, H.; Zhang, Z. Investigation of summer plankton community structure in Yuqiao Reservoir, Tianjin. J. Lake Sci. 2013, 25, 735-742.

37. Chen, S.R.; Guang-Hong, W.U.; Rui-Xian, S.U. Change characteristics of water quality and its impact factor at the Yuqiao Reservoir in Tianjin. Water Resour. Prot. 2011, 27, 27-30. 
38. Morrison, D.F. Multivariate Statistical Methods; McGraw-Hill Book Company: New York, NY, USA, 1967; pp. 299-309.

39. Kaiser, H.F. The application of electronic computers to factor analysis. Educ. Psychol. Meas. 1960, 20, 141-151. [CrossRef]

40. Chakrapani, G.J.; Subramanian, V. Heavy metals distribution and fractionation in sediments of the Mahanadi River basin, India. Environ. Geol. 1993, 22, 80-87. [CrossRef]

41. Borovec, Z. Trace elements levels in sediments of the Czech part of the Elbe River. Geojournal 1996, 40, 299-309. [CrossRef]

42. Loska, K.; Wiechuła, D. Application of principal component analysis for the estimation of source of heavy metal contamination in surface sediments from the Rybnik Reservoir. Chemosphere 2003, 51, 723-733. [CrossRef]

43. Li, X.; Xu, Y.; Zhao, G.; Shi, C.; Wang, Z.L.; Wang, Y. Assessing threshold values for eutrophication management using Bayesian method in Yuqiao Reservoir, North China. Environ. Monit. Assess. 2015, 187, 195. [CrossRef] [PubMed]

44. Xu, H.; Wang, L.; Wang, Y.; Tabuchi, J.-P. Non-point Pollution Estimation of Zhouhe River Basin. In Proceedings of the International Conference on Automation, Mechanical Control and Computational Engineering, Lijiang, China, 8 August 2015; pp. 1118-1122.

45. Xie, R.; Xu, Y.; Wang, Y. Temporal characteristics of eutrophication and pollution source analysis in Yuqiao reservoir. J. Water Resour. Water Eng. 2014, 25, 132-136.

46. Yuan, X.U.; Xie, R.; Wei, L.U. Evaluation and spatial characteristics of eutrophication in Yuqiao reservoir. J. Water Resour. Water Eng. 2014, 25, 1-6.

47. Zhang, H. Analysis on Treatment Solutions on External Pollution at Water Source of Yuqiao Reservoir. Anhui Agric. Sci. Bull. 2014, Z1, 101-105.

48. Meng, C.; Wang, Y.; Li, Y.; Zhou, J.; Li, Y.; Wu, J. Deteriorated Water Quality of Agricultural Catchments in South China by Net Anthropogenic Phosphorus Inputs. Sustainability 2017, 9, 1480. [CrossRef]

49. Wu, G.H.; Cao, S.S.; Yu, Y.Q. Distribution and enrichment of nutrients in superficial sediment in Tianjin typical waters. Environ. Sci. 2011, 30, 726-732.

50. Haopeng, L.; Shen, L.N. Distribution Characteristics of Carbon, Nitrogen and Phosphorous of River Surface and Pollution Status Evaluation of Sediments in Yuqiao Reservoir Basin, Tianjin. J. Anhui Agric. Sci. 2017, 45, 98-102.

51. Qiaoqiao, D.U.; Yan, K. Factor analysis of eutrophication in Yuqiao reservoir based on PCA. J. Water Resour. Water Eng. 2013, 24, 212-214.

52. Cong, H.B.L.; Huang, T.L.; Chuang, Y.L.I. Study on internal pollution of sediments in Yuqiao Reservoir. Water Resour. Prot. 2006, 22, 20-23.

53. Duan, W.; He, B.; Nover, D. Water Quality Assessment and Pollution Source Identification of the Eastern Poyang Lake Basin Using Multivariate Statistical Methods. Sustainability 2016, 8, 133. [CrossRef] 